\title{
Static Recrystallization Behavior and Mechanical Properties of Heterogeneous Nanostructured Duplex Phase Stainless Steel
}

\author{
Hiromi Miura $^{1, *}$, Masakazu Kobayashi ${ }^{1}$, Chihiro Watanabe $^{2}$, Natsuko Sugiura ${ }^{3}$ and Naoki Yoshinaga ${ }^{3}$ \\ ${ }^{1}$ Department of Mechanical Engineering, Toyohashi University of Technology, Toyohashi 441-8580, Japan \\ ${ }^{2}$ Faculty of Mechanical Engineering, Kanazawa University, Kanazawa 920-1192, Japan \\ ${ }^{3}$ Steel Research Labs., Nippon Steel Corp., Futtsu 293-8511, Japan
}

\begin{abstract}
Static recrystallization (SRX) behavior and tensile property of a 92\% cold-rolled duplex phase stainless steel were investigated. Lamellae structure, in which austenite $(\gamma)$ and ferrite $(\alpha)$ phases were complicatedly stacked, was developed by heavy cold rolling. The lamellae gradually changed to equi-axed fine grains during annealing at $1023 \mathrm{~K}$ and fully SRXed after $1.44 \times 10^{4} \mathrm{~s}(4 \mathrm{~h})$. Because of precipitation and its impediment of grain-boundary migration, grain coarsening was strongly suppressed even by prolonged annealing to $2.59 \times 10^{5} \mathrm{~s}(72 \mathrm{~h})$. While volume fraction of $\gamma$ phase was about $30 \%$ before annealing, it drastically increased up to $90 \%$. The transformed phase from $\gamma$ to $\alpha$ by heavy cold rolling re-transformed to stable equilibrium $\gamma$ at $1023 \mathrm{~K}$ and occurrence of SRX. No softening took place even with the occurrence of SRX and exhibited quite high $\mathrm{H}_{\mathrm{V}}$ hardness of $5.9 \mathrm{GPa}$ due to precipitation, which effectively suppressed grain growth. Tensile strength was barely changed before and after annealing and stayed about $1.5 \mathrm{GPa}$ on average, while ductility rapidly decreased. [doi:10.2320/matertrans.MT-M2019302]
\end{abstract}

(Received October 18, 2019; Accepted November 25, 2019; Published December 27, 2019)

Keywords: duplex phase stainless steel, cold rolling, heterogeneous nano-structure, annealing, static recrystallization, twin, phase transformation, mechanical property

\section{Introduction}

A lot of studies on severe plastic deformation (SPD) have been carried out ${ }^{1-7)}$ on how to attain ultrafine-grained (UFGed) metallic materials to achieve various specific properties as well as high strength. Sample sizes of UFGed metallic materials produced by means of SPD methods are, however, essentially too small to employ as structural ones. New innovative methods to fabricate samples large enough for structural components are therefore needed. The average grain size achieved by SPD methods is approximately $0.1 \sim$ $0.2 \mu \mathrm{m}$ at minimum, comparable to that of the subgrain. This suggests that the grain-refinement mechanisms taking place during SPD should be identified as continuous dynamic recrystallization, in which dislocation accumulation on to sub-boundaries and a gradual increase in the misorientation angles finally develops UFGs composed of high-angle grain boundaries. $^{3)}$

It is known that mechanical twinning dramatically accelerates grain refinement. ${ }^{6}$ ) This is because mechanical twinning having boundary spacing around $20 \mathrm{~nm}$ or less can instantly subdivide coarse initial grains. By employing nanometer-sized mechanical twinning in a $\mathrm{Cu}-\mathrm{Zn}$ alloy, a homogeneous nano-structured microstructure with an average grain size of $20 \mathrm{~nm}$ can be successfully fabricated by multidirectional forging. ${ }^{7}$ Applying a similar concept for grain fragmentation, dense introduction of mechanical twins can be carried out by simple heavy cold rolling of $\mathrm{Cu}-\mathrm{Be}$ alloy, resulting in a successfully developed UFGed structure with extraordinary high strength. ${ }^{8)}$ This suggests that the evolution of UFGed structures is drastically promoted in metallic materials with low stacking fault energy possibly because of the introduction of dense mechanical twins. Using these methods, Miura et al. successfully fabricated UFGed sheet stainless steels, employing mechanical twinning by means of

*Corresponding author, E-mail: miura@me.tut.ac.jp simple heavy cold rolling. ${ }^{9)}$ The heavily cold-rolled stainless steel possessed a specific microstructure subdivided by dense mechanical twinning, which they called a "heterogeneous nano-structure" in which all the microstructures were formed by deformation induced nanometer-scale ones. They exhibited excellent mechanical properties of tensile strength over 2.6 GPa and 5\% ductility after ageing. However, UFGed structures are known to be thermally unstable. ${ }^{10)}$

So far, however, there have been no studies on thermal stability and the static recrystallization (SRX) behavior of the heterogeneous nano-structured stainless steels as far as the authors know. A particular microstructure and mechanical properties originated from the heterogeneous nano-structure may be newly developed. In the present study, SRX behavior and changes in the mechanical properties of heavily coldrolled duplex phase stainless steel composed of heterogeneous nano-structure are systematically investigated.

\section{Experimental Method}

A SUS329J3L (DIN1.4462) duplex phase stainless steel with thickness of $6.25 \mathrm{~mm}$ was solution treated at $1523 \mathrm{~K}$ for $1 \mathrm{~h}$ followed by quenching. It was then heavily cold rolled to $0.5 \mathrm{~mm}$ thickness, i.e., $92 \%$ reduction. The chemical composition is shown in Table 1 . The volume fraction of austenite $(\gamma)$ phase after cold rolling was $70 \%$ measured by a ferrite meter. The cold-rolled sample was annealed at $1023 \mathrm{~K}$ for $72 \mathrm{~h}\left(2.5 \times 10^{5} \mathrm{~s}\right)$ in a vacuum furnace. The evolved microstructures before and after annealing were investigated by transmission electron microscopy (TEM) and scanning electron microscopy equipped with electron back scatter diffraction analyzer (SEM-EBSD) after mechanical and electritical polishing. For the observation from transvers direction (TD), foils were prepared using ion milling apparatus. Mechanical properties were examined using micro-Vickers hardness tester and Instron-type mechanical testing machine. Tensile specimens with gauge dimensions of 
Table 1 Chemical composition of a supplied SUS329J3L (DIN1.4462) duplex phase stainless steel in mass\%.

\begin{tabular}{ccccccccccccc}
\hline $\mathrm{C}$ & $\mathrm{Si}$ & $\mathrm{Mn}$ & $\mathrm{P}$ & $\mathrm{S}$ & $\mathrm{Al}$ & $\mathrm{Ni}$ & $\mathrm{Cr}$ & $\mathrm{Mo}$ & $\mathrm{N}$ & $\mathrm{O}$ & $\mathrm{Fe}$ \\
\hline 0.020 & 0.47 & 1.77 & 0.018 & 0.0009 & 0.026 & 5.50 & 22.01 & 3.01 & 0.1260 & 0.0018 & Bal. \\
\hline
\end{tabular}

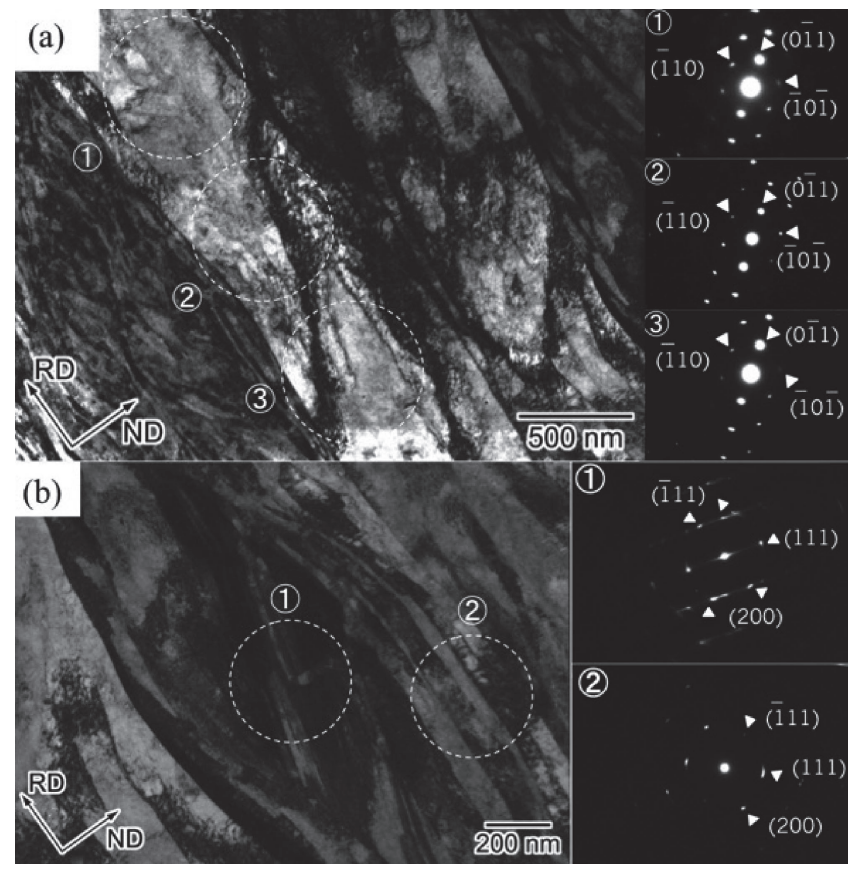

Fig. 1 TEM photographs of (a) partially mixed region of ferrite and austenite, and (b) austenite region. Corresponding selected area-diffraction patterns are also shown using circle numbers. RD and ND indicate rolling and normal directions. The microstructure of ferrite only is also displayed in Fig. 4(a) which was observed at a lower magnification.

$6.0 \times 3.0 \times 0.5 \mathrm{~mm}^{3}$ were electro-discharge machined from the rolled sheet. Tensile test was carried out parallel to the rolling direction $(\mathrm{RD})$ at an initial strain rate of $2.5 \times$ $10^{-3} \mathrm{~s}^{-1}$ at room temperature.

\section{Results and Discussion}

\subsection{Microstructure before annealing}

Figure 1 displays TEM micrographs of the $92 \%$ coldrolled duplex phase stainless steel. The feature of microstructure was different depending on the phase; low-angle lamellae at $\alpha$ region (Fig. 1(a)) and a typical "heterogeneous" nano-structure at austenite $\left(\gamma\right.$ region (Fig. 1(b)) ${ }^{9)}$ From the selected area diffraction patterns, specific development of substructure in the $\alpha$ region, and twins and low angle lamellae in the $\gamma$ could be recognized. That is, simple lamellae with an average boundary spacing of about $200 \mathrm{~nm}$, and having dislocation substructure were developed in the $\alpha$ region, whereas a complex "eye"-shaped twin domain was embedded in low-angle lamellae with boundary spacing of an average $170 \mathrm{~nm}$ in the $\gamma$ region. The latter is known to evolve by mechanical twinning during heavy cold-rolling of both austenitic and duplex phase stainless steels. ${ }^{9}$ The twinboundary spacing inside of the eye-shaped twin domains was about $80 \mathrm{~nm}$. While it is reported that the eye-shaped twin domain is surrounded by shear bands, ${ }^{9}$ ) this feature was

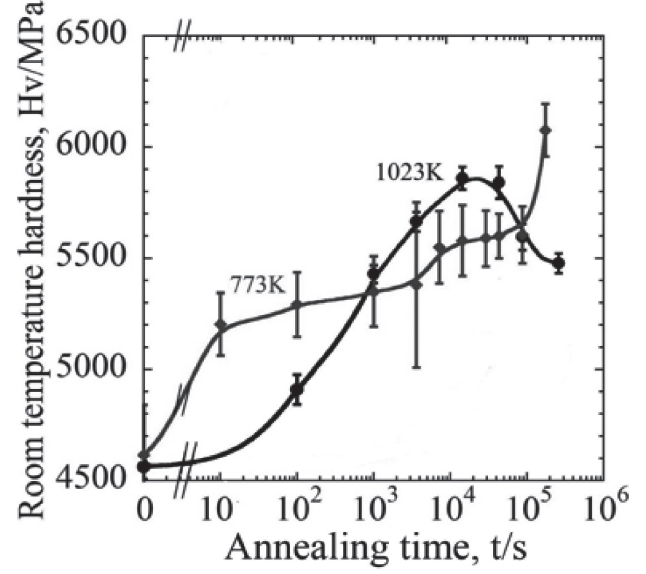

Fig. 2 Change in the hardness of the heavily cold-rolled duplex phase stainless steel during annealing at $1023 \mathrm{~K}$. The result annealed at $773 \mathrm{~K}$ is also displayed for comparison. ${ }^{9}$

not clearly observed in Fig. 1(b). Therefore, a quite complicated nanometer-sized structure was evolved by alternative stacking of $\alpha$ and $\gamma$ phase lamellae. Furthermore, their feature drastically changes depending on the phase.

\subsection{Annealing behavior and microstructural change}

Change in the hardness during annealing at $1023 \mathrm{~K}$ was investigated and the result as well as that at $773 \mathrm{~K}$ for comparison $^{9)}$ is shown in Fig. 2. Hardness rapidly increased to a peak around $1.44 \times 10^{4} \mathrm{~s}(4 \mathrm{~h})$, and then gradually decreased by prolonged annealing. As will be shown later, SRX extensively took place after $7.2 \times 10^{3} \mathrm{~s}(2 \mathrm{~h})$ and the observed hardening in spite of SRX was affected by dense precipitation. SRX was not detected at all at $773 \mathrm{~K} .{ }^{9}{ }^{9}$

Figure 3 shows the summarized results of SEM-EBSD observation. Because of the large strains stored and the high dislocation density, no detected area indicated by black contrast appeared before annealing (Fig. 3(a)). Although the texture appears also to change, the reason is not discussed here because of quite small areas analyzed and insufficient number of grains for statistical analysis. After annealing for $1.44 \times 10^{4} \mathrm{~s}(4 \mathrm{~h})$, the sample seemed to be fully SRXed and had an average grain size approximately of $2 \mu \mathrm{m}$ (Fig. 3(b)). It was interesting to see that most of the $\alpha$ phase/grains transformed into $\gamma$ one (Fig. 3(d)).

The evolved microstructure before and after annealing was observed by TEM from TD and the typical microstructures are displayed in Fig. 4. The as-rolled sample showed a typical $\alpha$ lamellae structure with an average boundary spacing of $200 \mathrm{~nm}$ (Fig. 4(a)). Of course, some areas were composed of alternative stacking of $\alpha$ and $\gamma$ phases, as already shown in Fig. 1. However, most of them were changed to equi-axed fine grains by SRX. The phase transformation from $\alpha$ to $\gamma$ could be recognized by the 

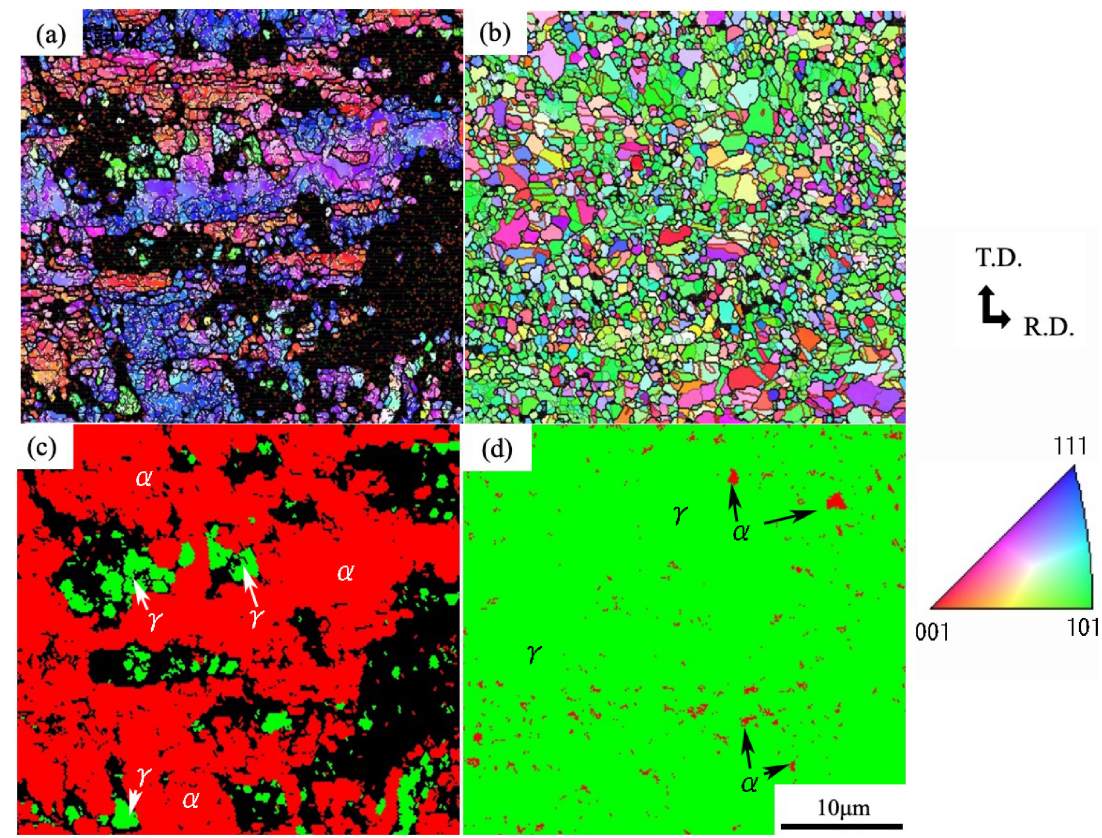

Fig. 3 Microstructural changes on the normal plane during annealing at $1023 \mathrm{~K}$ observed using SEM-EBSD; IPF maps of (a) before annealing and (b) annealed for $1.44 \times 10^{4} \mathrm{~s}(4 \mathrm{~h})$, and the corresponding phase maps; (c) before annealing and (d) annealed for $1.44 \times 10^{4} \mathrm{~s}(4 \mathrm{~h})$, respectively. $\alpha$ and $\gamma$ phases are indicated by red and green colors in (c) and (d). Observation and color decoding are parallel to N.D.

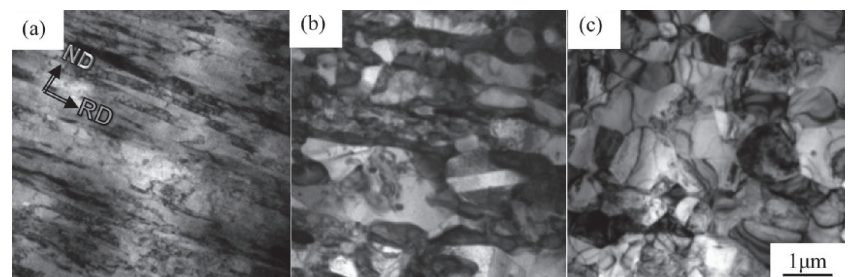

Fig. 4 Change in the microstructure during annealing at $1023 \mathrm{~K}$; (a) as rolled, and annealed for (b) $2 \mathrm{~h}$ and (c) $72 \mathrm{~h}$.

formation of annealing twins in the SRXed grain interior (Figs. 4(b), (c)) as well as the phase maps in Figs. 3(c), (d). It was revealed by the microscopic observation using TEM that recrystallization was not still completed after annealing for $7.2 \times 10^{3} \mathrm{~s}(2 \mathrm{~h})$. Full SRX was actually achieved after $1.44 \times 10^{4} \mathrm{~s}(4 \mathrm{~h})$ annealing (see Fig. 5). It is also interesting to note that the SRXed grains hardly coarsened even by the prolonged annealing. The average grain sizes after annealing for $7.2 \times 10^{3} \mathrm{~s}(2 \mathrm{~h})$ and $2.59 \times 10^{5} \mathrm{~s}(72 \mathrm{~h})$ are roughly 1 and $2 \mu \mathrm{m}$ respectively. The above results suggest that a duplex phase stainless steel composed of thermally stable equi-axed fine grains could be attained by occurrence of a truly homogeneous nucleation.

The reason for the increase in the hardness during annealing and SRX was investigated by TEM observation at higher magnification, and a typical photograph is shown in Fig. 5. It can be seen that precipitates with dark contrast were densely distributed in the SRXed grains. Impediment of grain-boundary migration and grain coarsening by precipitates is now well known. ${ }^{11)}$ Our experiment confirmed, therefore, that suppression of grain coarsening as well as hardening during annealing was induced by precipitation. Although the composition and structure of the precipitates could not be clearly identified by TEM and X-ray

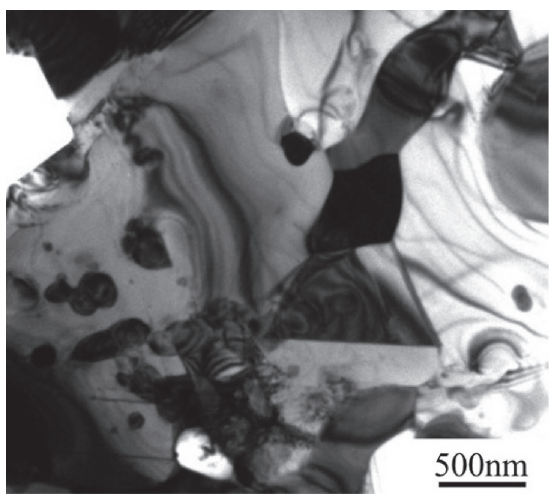

Fig. 5 A TEM photograph of the duplex phase stainless steel fully recrystallized after annealing for $1.44 \times 10^{4} \mathrm{~s}(4 \mathrm{~h})$ at $1023 \mathrm{~K}$. Many precipitates can be seen.

diffractometer analyses due to the complicated chemical compositions and overlap of diffraction peaks, it was assumed that they would be $\sigma$ phase and/or $\mathrm{M}_{23} \mathrm{C}_{6}$ from the studies on precipitates in stainless steels. ${ }^{12}$ We also carried out a semi-qualitative examination about the formation of $\sigma$ phase at equilibrium state using Thermo-Calc software and it suggested high mole fraction of the $\sigma$ phase at $1023 \mathrm{~K}$ up to $25 \%$ and $\gamma$ phase rest, furthermore, virtually no formation of $\alpha$ phase and $\mathrm{M}_{23} \mathrm{C}_{6}$. Nevertheless, the results of SEM-EBSD analysis in Fig. 3 indicated the formation of $\alpha$ phase. In addition, the observed rather coarse grains without annealing twins in Figs. 4(b), (c) and Fig. 5 were presumably $\alpha$ grains. This may imply a non-equilibrium state of the finegrained SRX structure. Finally, the results confirmed that $\sigma$ phase strongly impeded grain coarsening.

When comparing Figs. 2, 4 and 5, observation showed that the notable hardening in spite of full SRX during annealing was derived from precipitation. The softening that appeared 
after $10^{5} \mathrm{~s}$ should be, therefore, induced by ripening of precipitates to reduce the distribution density in addition to slight grain coarsening. Both a decrease in density of precipitates and grain growth are generally known to cause softening.

It is reported that a UFGed structure exhibits unusual thermal instability and SRX can take place at temperatures well below $0.5 \mathrm{Tm}$, i.e., much less than half of melting point. ${ }^{10)}$ However, in the present heterogeneous nanostructured sample, full SRX occurred after annealing for a long time, even at $1023 \mathrm{~K}(0.7 \mathrm{Tm}) .1023 \mathrm{~K}$ is essentially a high enough temperature for SRX to take place in almost all conventional stainless steels. Furthermore, no SRX was observed by the annealing at $\left.773 \mathrm{~K} .{ }^{9}\right)$ This indicates that the development of a heterogeneous nano-structure does not spoil thermally stability. If anything, it possesses rather good thermal stability. A superior property would be affected by high thermal stability of twins. ${ }^{13)}$

\subsection{Change in the tensile properties by annealing}

The samples before and after annealing were tensile tested along RD. The flow curves are shown in Fig. 6. The as-coldrolled sample exhibited quite high tensile strength of about $1.55 \mathrm{GPa}$. However, this value is lower than the $1.8 \mathrm{GPa}$ attained in a duplex phase stainless steel with same chemical composition and fabricated by simple heavy cold-rolling to 92\%. ${ }^{9)}$ Miura et al. suggested eye-shaped twin domain played an important role in strength. ${ }^{9}$ ) Aoyagi et al. calculated the effect of the eye-shaped twin domain on strengthening by multi-scale simulation, and theoretically showed that strength increases as the volume fraction of the eye-shaped twin domain increases. ${ }^{14)}$ While we could not compare the difference between the volume fractions of the eye-shaped twin domains in the corresponding two samples, it is reasonable to suppose that the volume fraction of the eyeshaped twin domains in the present sample must be lower than that in the previous report. ${ }^{9)}$ Such differences could easily be caused by the change of rolling process because mechanical twinning is one of stress relief mechanisms.

The tensile strength was not largely changed depending on annealing time, and was roughly $1.5 \mathrm{GPa}$. This tendency

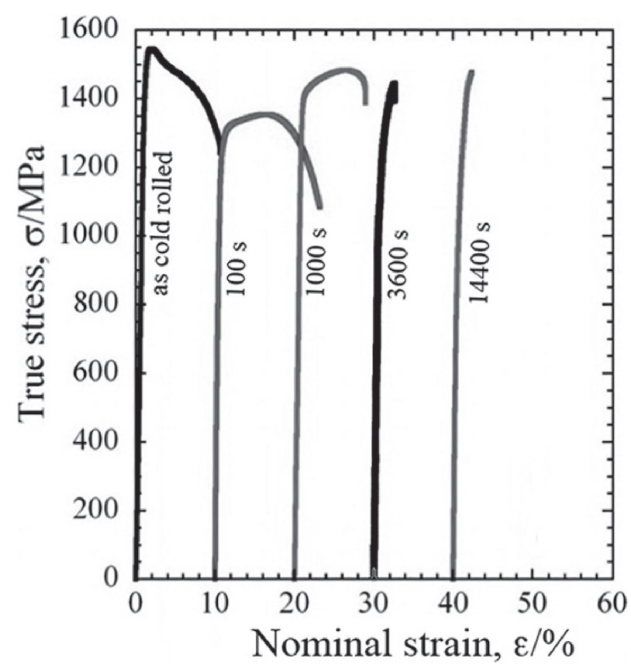

Fig. 6 Results of tensile tests of the cold-rolled duplex phase stainless steels before and after annealing at $1023 \mathrm{~K}$. should be because dense distribution of precipitates and still more full SRX occurred by annealing (Fig. 4). However, ductility rapidly dropped with increased annealing time. The loss of ductility was caused by dense distribution and coarsening of precipitates. Nevertheless, it should be noted that the dense formation of $\sigma$ phase largely contributed to improve thermal stability of fine-grained structure, which effectively impeded grain coarsening even by prolonged annealing at $1023 \mathrm{~K}$ and kept the tensile strength to be around 1.5 GPa.

\section{Conclusions}

(1) The cold-rolled sample was compsed of a complicated nanometer-scale structure where ferrite $(\alpha)$ and austenite $(\gamma)$ lamellae were alternatively stacked. The boundary spacings of $\alpha$ and $\gamma$ lamellae were $200 \mathrm{~nm}$ and $170 \mathrm{~nm}$, respectively. Further, eye-shaped twin domains were embedded in the $\gamma$ lamellae.

(2) Even while annealing at $1023 \mathrm{~K}$ caused full recrystrallization, it exhibited good thermal stability. The recrystallized grain size was hardly changed, between 1 and $2 \mu \mathrm{m}$, even by prolonged annealing for $2.59 \times$ $10^{5} \mathrm{~s}(72 \mathrm{~h})$. Such high-thermal stability was understood from the impediment of grain coarsening by high densely introduced $\sigma$ phase precipitation.

(3) Even after recrystallization and annealing for $72 \mathrm{~h}$, the tensile strength was kept around $1.5 \mathrm{GPa}$, while ductility rapidly decreased.

\section{Acknowledgments}

Some of the authors, H. Miura, M. Kobayashi, C. Watanabe, appreciate the financial support given by Japan Science and Technology Agency (JST) under IndustryAcademia Collaborative R\&D Program "Heterogeneous Structure Control: Towards Innovative Development of Metallic Structural Materials" (Grant \#: JPMJSK1413).

\section{REFERENCES}

1) Z. Horita (ed.): Nanomaterials by severe plastic deformation, Mater. Sci. Forum 503-504, (Trans Tech Publications, Switzerland, 2006).

2) R.Z. Valiev: Mater. Trans. 55 (2014) 13-18.

3) T. Sakai, A. Belyakov, R. Kaibyshev, H. Miura and J.J. Jonas: Prog. Mater. Sci. 60 (2014) 130-207.

4) N. Tsuji: Tetsu-to-Hagané 88 (2002) 359-369.

5) J. Ivanisenko, R. Kulagin, V. Fedorov, A. Mazilkin, T. Scherer, B. Baretzky and H. Hahn: Mater. Sci. Eng. A 664 (2016) 247-256.

6) Y. Nakao and H. Miura: Mater. Sci. Eng. A 528 (2011) 1310-1317.

7) H. Miura, Y. Nakao and T. Sakai: Mater. Trans. 48 (2007) 2539-2541.

8) H. Miura and R. Morita: J. Jpn. Res. Inst. Adv. Copper-base Mater. Technol. 52 (2013) 121-125.

9) H. Miura, M. Kobayashi, Y. Todaka, C. Watanabe, Y. Aoyagi, N. Sugiura and N. Yoshinaga: Scr. Mater. 133 (2017) 33-36.

10) M.M. Abramova, N.A. Enikeev, X. Sauvage, A. Etienne, B. Radiguet, E. Ubyivovk and R.Z. Valiev: Rev. Adv. Mater. Sci. 43 (2015) 83-88.

11) F.J. Humphreys and M.G. Ardakani: Acta Mater. 44 (1996) 2717-2727.

12) Y. Maehara, M. Koike, N. Fujino and T. Kunitake: Tetsu-to-Hagané 67 (1981) 577-586.

13) H. Miura, T. Sakai, R. Mogawa and J.J. Jonas: Philos. Mag. 87 (2007) 4197-4209.

14) Y. Aoyagi, C. Watanabe, M. Kobayashi, Y. Todaka and H. Miura: Tetsu-to-Hagané 105 (2019) 262-271. 